\title{
Twenty years of childhood coeliac disease in The Netherlands: a rapidly increasing incidence?
}

\author{
E K George, M L Mearin, H C M Franken, R H J Houwen, R A Hirasing, \\ J P Vandenbroucke
}

\begin{abstract}
Background-The incidence of coeliac disease varies internationally.

Aims-To assess the incidence of childhood coeliac disease in The Netherlands and to study the clinical features and the presence of associated disorders.

Subjects-Identified cases of childhood coeliac disease in The Netherlands in 1993-4 by means of the Dutch Paediatric Surveillance Unit.

Methods-Inclusion criteria were born in The Netherlands, diagnosed with at least one biopsy of the small bowel in 1993-4 and age at diagnosis $0-14$ years. The data were cross checked by the Dutch Network and National Database of Pathology and compared with data from a previous study on childhood coeliac disease, 1975-90.

Results-A total of 193 coeliac patients were identified by means of the Surveillance Unit, another 20 through the National Database of Pathology. The mean crude incidence rate of diagnosed childhood coeliac disease was $0 \cdot 54 / 1000$ live births, which is in the range of rates found in other western European countries and significantly higher than the mean crude incidence rate of $0 \cdot 18 / 1000$ live births found in The Netherlands in 1975-90. The clinical presentation was classic: chronic diarrhoea, abdominal distension, and growth failure. Associated disorders were present in $11.7 \%$ of the cases.

Conclusions-The incidence of diagnosed childhood coeliac disease in The Netherlands seems to have increased significantly during the past few years. In a period of 20 years no significant changes could be found in the clinical picture at presentation of coeliac disease in Dutch children.
\end{abstract}

(Gut 1997; 40: 61-66)

Keywords: coeliac disease, epidemiology, incidence, The Netherlands.

The variations and changes in the incidence of childhood coeliac disease throughout Europe have been described extensively. ${ }^{1-8}$ Several hypotheses relating to differences in feeding practices between countries, ${ }^{9}$ a changing feeding pattern within the same country, ${ }^{10}{ }^{11}$ or a change in the clinical picture of coeliac disease, ${ }^{4} 1213$ have been proposed to explain these variations. In a previous study we retrospectively investigated the epidemiology of childhood coeliac disease in a defined area

of The Netherlands in 1975-90. ${ }^{14}$ Two con- clusions were drawn from that study. Firstly, the crude incidence of childhood coeliac disease, $0 \cdot 18 / 1000$ live births, was low in comparison with other European countries. Secondly, there was a significant increase in incidence rate from 1976 onward.

The aim of the present study was to assess the incidence of childhood coeliac disease prospectively on a national level and to study the clinical features of the presence of associated disorders in Dutch coeliac children over a period of 20 years. We also wanted to investigate whether the increasing trend of the incidence would continue, and, if so, whether we could explain this phenomenon. Therefore coeliac disease was included in the Dutch Paediatric Surveillance Unit. ${ }^{15}$

\section{Methods}

THE DUTCH PAEDIATRIC SURVEILLANCE UNIT This unit was founded in 1992 under the auspices of the Dutch Society for Paediatrics, following the example of the British Paediatric Surveillance Unit. ${ }^{16}$ The aims of the unit are to promote scientific research by involving all Dutch paediatricians in the surveillance of several disorders, to supply information on the healthcare system, and to improve the quality of health care on a primary, secondary, or tertiary level to acquire insight in background, prognosis, treatment, and prevention of the diseases concerned.

\section{DATA COLLECTION}

New and suspected cases of childhood coeliac disease throughout The Netherlands were registered prospectively during 1993 and 1994. All paediatricians working in general hospitals were requested each month to report to the Dutch Paediatric Surveillance Unit the initials, sex, and date of birth of the children in whom they had diagnosed or suspected coeliac disease. In the eight university hospitals a specific contact person was nominated to report. Private paediatric clinics do not exist in The Netherlands. When a suspected or diagnosed case of coeliac disease was reported, the unit contacted one of us (EKG). Then we sent a questionnaire to the paediatrician involved. $\mathrm{He}$ or she was asked to provide us with the data concerning sex, place of birth, pattern of breastfeeding, age at gluten introduction, onset of symptoms, symptoms at presentation, age at diagnosis, number of and date of the first biopsy of the small intestine, associated diseases, and family history of coeliac disease. If the paediatrician did not return the
Dr M Mearin, University Hospital Leiden, Department of Paediatrics, J6-S-220, PO Box 9600 Netherlands.

Accepted for publication 28 August 1996 
questionnaire, contact was made again by letter or telephone. The privacy of the patients was guaranteed throughout the study, as was the case in our retrospective study in which informed consent was obtained to study the medical files of the coeliac patients.

To include a patient in the study the following criteria were used: (1) born in The Netherlands; (2) diagnosis of coeliac disease based on at least one biopsy of the small intestine, showing (sub)total villous atrophy; (3) age at diagnosis (first diagnostic biopsy of the small intestine) between 0-14 years; (4) coeliac disase diagnosed between 1 January 1993 and 1 January 1995. These inclusion criteria were comparable with the criteria used in our retrospective study, with the difference that the diagnosis had been made in the period 1975-90. The diagnostic criteria we used did not fully meet the requirements of the original or revised criteria for the diagnosis of coeliac disease established by the European Society of Paediatric Gastroenterology and Nutrition, which require histological ${ }^{17}$ or clinical ${ }^{18}$ follow up. This is because only new or suspected cases of coeliac disease were reported to the Dutch Paediatric Surveillance Unit. Demographic and epidemiological data regarding the general population were provided by The Netherlands Central Bureau of Statistics. ${ }^{19}$ The emigration and immigration rates per 1000 inhabitants in the general Dutch population have remained stable over the past 10 years: in 1985 the immigration rate was $5.6 \%$, in $19946.5 \%$; in 1985 the emigration rate was $3 \cdot 8 \%$, in $19934.0 \%$.

\section{ASCERTAINMENT}

The data obtained via the Dutch Paediatric Surveillance Unit were cross checked by means of the information provided by the Dutch Network and National Database of Pathology, as were the data from our retrospective study. In this database all pathological specimens taken in The Netherlands are registered anonymously (sex, age, and date of biopsy) and it comprises $100 \%$ of the Dutch pathological laboratories. The data thus obtained were taken into account in the calculations of the crude incidence of childhood coeliac disease.

DATA REPORT AND STATISTICAL ANALYSIS

The crude incidence rate of suspected childhood coeliac disease was calculated as a ratio using the number of children aged $0-14$ years who developed villous atrophy suggestive of coeliac disease in 1993 and 1994 in our retrospective study 1975 through 1990 as the numerator, and the number of live births in these years as the denominator, expressed per 1000. A $\chi^{2}$ test for contingency tables, including comparison of figures obtained in different years in The Netherlands, was used. A possible linear effect between the clinical symptoms over a period of 20 years was tested with the Mantel-Haenszel test for linear association; $p<0.05$ was accepted as being significant. Results are expressed as mean values (SD).

\section{Results}

RESPONSE

Of the approximately 400 Dutch paediatricians who were contacted by the Dutch Paediatric Surveillance Unit, 91\% returned the monthly report card in 1993 and $93 \%$ in 1994. The non-response was mostly incidental: in 1993 six and in 1994 two paediatricians did not respond at all. In 1993 and 1994 all paediatricians who had diagnosed or suspected coeliac disease and who were subsequently contacted by us, returned the questionnaire, resulting in a $100 \%$ response.

\section{INCIDENCE RATE}

In 1993195742 children were born alive in The Netherlands and 88 children were diagnosed as coeliac patients according to the inclusion criteria, resulting in a crude incidence rate of $0 \cdot 45 / 1000$. In 1994 the total number of live births was 195616 and a total of 105 children were diagnosed as coeliac patients, resulting in a crude incidence rate of $0 \cdot 54 / 1000$ live births. Compared with our previous findings the increase was highly significant $(p<0.001$; Fig 1$)$.

The incidence rates of childhood coeliac disease in the 12 Dutch provinces were mostly consistent with the overall incidence rate, varying between 0.30 and $0.50 / 100$ live births over the period 1993-4. For instance, in the province of Noord-Holland (Amsterdam) and ZuidHolland (Leiden, Rotterdam) the incidence rates were 0.40 and $0.43 / 1000$ live births respectively. One of the highest incidence rates was found in the province of Utrecht $(0 \cdot 70 / 1000)$, the lowest in Zeeland $(0 \cdot 22 / 1000)$.

\section{ASCERTAINMENT}

All new cases of coeliac disease reported in 1993-4 could be traced back to the Dutch Network and National Database of Pathology, with the exception of three. In one case it was found out later that the patient was erroneously booked out under 'colonic biopsy', in another case, after contacting the paediatrician again, it seemed that after all no biopsy of the small intestine had in fact been performed. In one case the reason remained unclear. On the other hand, in the Database for Pathology we found 39 cases under the age of 15 with (sub)total

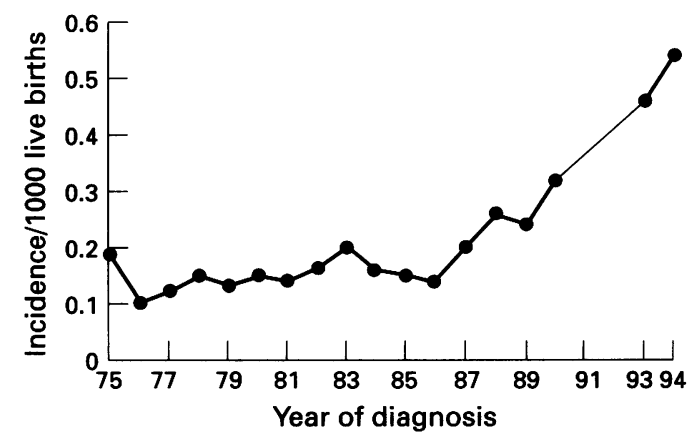

Figure 1: Incidence of childhood coeliac disease in The Netherlands during the period 1975-94. 
villous atrophy of the small bowel, which we think should have been reported to the Dutch Paediatric Surveillance Unit. After a cross check it indeed seemed that 20 cases had incorrectly not been reported due to the fact that this had been forgotten, and that 17 cases rightly had not been reported, because of the fact that another diagnosis had been established afterwards. In the remaining two cases no answer was obtained. Including the 20 patients found by means of the Dutch Database of Pathology the overall crude incidence rate of coeliac disease for 1993-4 was $0.54 / 1000$ live births. Only in one case was there a discrepancy between the histology of the biopsy as reported by the paediatrician and as found in the Database of Pathology.

FOLLOW UP

To date all the cases have been ascertained again by means of the Dutch National Database for Pathology. This ascertainment showed that 53 of the 88 children diagnosed in 1993 $(60 \cdot 2 \%)$ underwent their second biopsy during 1994 or 1995 and that 31 of the 105 children diagnosed in $1994(29.5 \%)$ underwent their second biopsy in 1995. These patients were from different centres all around the country. In 79 of the 84 second biopsies of the small bowel $(94 \%)$ a total or nearly total histological improvement was found.

CLINICAL PICTURE

Table I presents some characteristics of the clinical picture at the time of diagnosis of the

TABLE I Clinical picture at time of diagnosis of some coeliac children during the study period 1993-4 compared with 1975-90 14

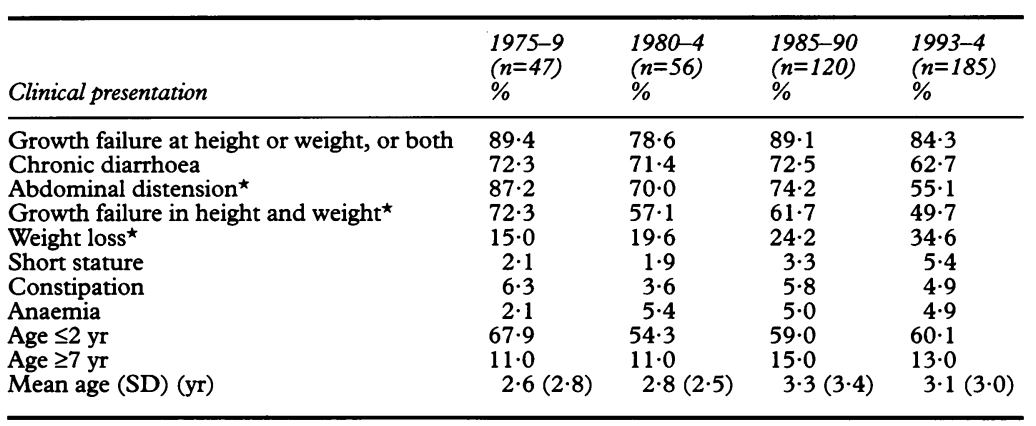

«Significant linear trend $(p<0 \cdot 05)$.

TABLE II Associated diseases in children diagnosed with coeliac disease

\begin{tabular}{lll}
\hline & $1975-90$ & $1993-4$ \\
$n=223(65 \%) * / 342$ & $n=179(93 \%) * / 193$ \\
Disease & $n$ & $n$ \\
\hline Cows' milk allergy & 2 & 3 \\
Diabetes mellitus type I & 3 & $1 \dagger$ \\
Down's syndrome & 2 & 2 \\
Selective IgA deficiency & 5 & 1 \\
Juvenile chronic arthritis & 2 & 1 \\
Dermatitis herpetiformis & 0 & 1 \\
Cystic fibrosis & 2 & 0 \\
Epilepsy & 1 & 0 \\
Chronic autoimmune hepatitis & 1 & $21(11 \cdot 7 \%)$ \\
Alopecia & 2 & \\
Total & $20(8.9 \%)$ & \\
\hline
\end{tabular}

*Information available.

tnot included six patients with Down's syndrome found after screening. ${ }^{20}$
Dutch coeliac children during the past 20 years. In the 193 patients (boys:girls $1: 2 \cdot 1$ ) identified during 1993-4 growth failure (defined as a deviation equal or larger than -2 SD from their growth line), either in height, or weight, or in both, was the most common presenting symptom. At presention $58.9 \%$ of children were below the 10 th percentile for weight, and $39 \cdot 1 \%$ were below the 10 th percentile for height. However, when compared with the clinical presentation found in the period 1975-90, a significant linear trend was found: presentation of abdominal distension and growth failure in both height and weight has become less common in time, whereas weight loss alone without deviating height, has become more common. No significant trend could be demonstrated when growth failure in height, or weight, or in both was analysed. During 1993-4 an atypical (fatigue, anaemia, anorexia) or monosymptomatic (short stature, anaemia) presentation was found in $7.0 \%$ of the cases. Constipation and anaemia were found in $4.9 \%$ but always in combination with other symptoms such as growth failure, abdominal distension, diarrhoea, or vomiting, with the exception of one child, who also had Down's syndrome and was detected by screening; she had severe constipation as the only presenting symptom.

Information on diseases associated with coeliac disease was available in $93 \%$ of the 193 children diagnosed in 1993-4. These associations were found in $11.7 \%$ of the children, in comparison with $8.9 \%$ found in $65 \%$ of the children diagnosed in 1975-90 (NS; Table II). Seven children with both coeliac disease and Down's syndrome were encountered. Six were identified by screening and one presented with classic coeliac symptoms and was subsequently diagnosed. Two of these six patients identified by screening were asymptomatic; the other four had symptoms such as diarrhoea, failure to thrive, and lethargy, which in the past had repeatedly been attributed to Down's syndrome. First degree relatives with coeliac disease were present in the case of $4.8 \%$ of the coeliac children in 1993-4 and $7 \cdot 1 \%$ in 1975-90 (NS).

Screening methods for coeliac disease to select patients for biopsy of the small intestine, were applied for most children diagnosed in 1993-4. The use of serological screening tests, especially the antigliadin antibody test, has increased significantly since 1975 , by contrast with the functional xylose test, the use of which has decreased ( $p<0.05)$; (Fig 2).

Table III shows data on breast feeding in our study group compared with the general population. During 1975-90, at day 90 coeliac children received breast feeding comparable with the children of the general population. However, in 1993-4 coeliac children received significantly more breast feeding than the children in the general population.

Wheat products were introduced in $85.2 \%$ of the children after the age of 6 months. At the age of 3 months only $1 \cdot 7 \%$ of the children had gluten introduced into the diet. 


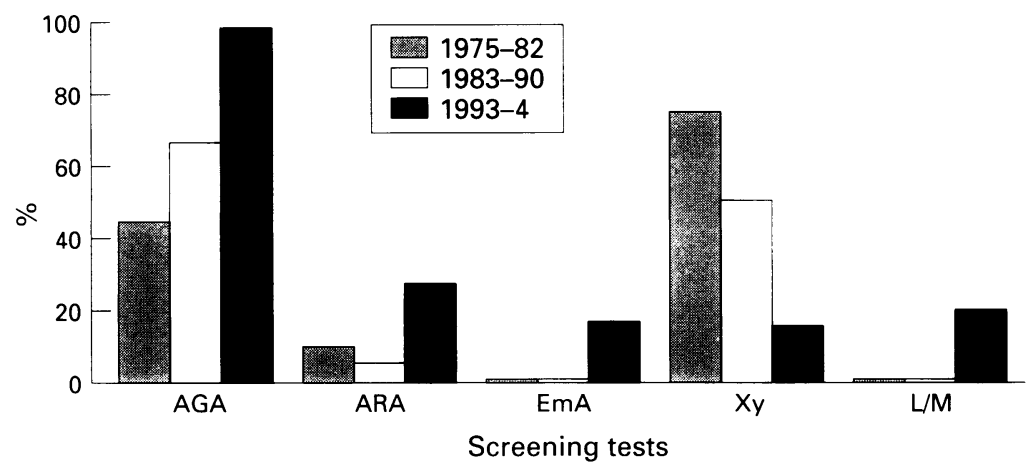

Figure 2: Serological and functional tests used in the screening for coeliac disease during the period 1975-94. $A G A=$ antigliadin; $A R A=$ antireticulin; Em $A=$ antiendomysium serum antibodies; $X y=x y l o s e ; L / M=$ lactulose/mannitol sugar absorption test.

\section{Discussion}

INCIDENCE OF CHILDHOOD COELIAC DISEASE THE NETHERLANDS

The most accurate measure to calculate the incidence of a disease is the cumulative incidence rate, in which a (birth) cohort is followed up for a period of time and the new cases of the disease of interest are registered. In other words, the newly diagnosed cases derive from the cohort that is being followed up. A study period of two years, as in this study is, however, too short for follow up of one birth cohort, even though in the case of coeliac disease most children in both our studies $60 \%$ are diagnosed before the age of 2 . Therefore we computed the 'crude' incidence rate, using the number of live births in the study period as denominator. This implies that the numerator - the newly diagnosed cases - does not derive from the denominator and that it is in fact a ratio rather than a rate. Another drawback of the calculation of the crude incidence rate is that calculation of the $95 \%$ confidence intervals would provide a false accuracy: the crude incidence rate is already an estimate, as the numerator is no part of the denominator. However, using the crude incidence rate it is possible to compare the results of this study with those from other European countries ${ }^{1}$ and with our earlier study concerning the epidemiology of childhood coeliac disease in $1975-90 .{ }^{14}$ In this previous study we found a mean crude incidence rate for diagnosed childhood disease in $1975-90$ of $0 \cdot 18 / 1000$ live births, which was significantly lower than the incidence rates found in most other European countries for that period, although in line with data from Denmark. ${ }^{6}$ A significant increase in reported incidence was found from 1976 to 1990 ; the incidence rose from $0 \cdot 10 / 1000$ to $0 \cdot 32 / 1000$ live births. This increase seems to continue, as we found a crude incidence rate of $0 \cdot 54 / 1000$

TABLE III Percentages of coeliac children and Dutch children receiving breast feeding on day 90 from 1975 to 94

\begin{tabular}{lclll}
\hline & $\begin{array}{l}1975-9 \\
\%\end{array}$ & $\begin{array}{l}1980-4 \\
\%\end{array}$ & $\begin{array}{l}1985-90 \\
\%\end{array}$ & $\begin{array}{l}1993-4 \\
\%\end{array}$ \\
\hline Coeliac disease & $\begin{array}{r}9 \cdot 1 \\
\text { Dutch children }\end{array}$ & $\begin{array}{l}25 \cdot 0^{\star} \\
27 \cdot 1^{\star}\end{array}$ & $\begin{array}{l}33 \cdot 6^{\star} \\
31 \cdot 9^{\star}\end{array}$ & $\begin{array}{l}38 \cdot 7 \dagger \\
24 \cdot 8\end{array}$ \\
\hline
\end{tabular}

${ }^{\star} \mathrm{p}<0.05$ ( $v$ previous period) tp<0.001 (v 1993-4 Dutch children). in 1993-4 (Fig 1), which is now in the range of other west European countries. ${ }^{1}$ Cases were included after their first diagnostic biopsy of the small bowel, which may mean that the diagnosis of coeliac disease was rejected at histological or clinical follow up of the patient. Because we did not contact the reporting paediatricians again after a certain period of time, we cannot provide data on clinical follow up. However, by means of the Dutch National Database for Pathology, we have been able to obtain information on histological follow up of $60.2 \%$ of the children diagnosed in 1993 and of $29.5 \%$ of the children diagnosed in 1994 . This follow up showed that a total or nearly total histological improvement was found in $94 \%$ of the performed biopsies, suggesting that only a minority of the children will not have coeliac disease later on.

Although in most Dutch provinces an incidence rate of childhood coeliac disease was found during 1993-4 in the range of 0.30 to $0 \cdot 50 / 1000$ live births, some provinces showed differences in the incidence rate - for instance, $0 \cdot 70 / 1000$ live births in Utrecht and $0 \cdot 22 / 1000$ in Zeeland. The high incidence in Utrecht might in part be historically explained, as it was at the University Hospital, Utrecht that Dicke discovered that wheat was the component in the normal diet toxic to persons with coeliac disease and traditionally there has been special interest in coeliac disease at this centre since. ${ }^{21}$ The low incidence in Zeeland might be explained by the fact that it is a small province with few paediatric beds, no university hospital, and that the nearest referral center, the University Hospital, Rotterdam, is relatively far away.

The geographical variations in incidence rates in The Netherlands could also be because of differences in the evaluation of the biopsy specimens by different pathologists throughout the country. In our previous study we found similar geographical variations in incidence rates, although at significantly lower incidence levels. ${ }^{14}$

The steady rise in the mean incidence rate of childhood coeliac disease in The Netherlands could be explained by several mechanisms. One possible explanation is that the rising incidence of coeliac disease is apparent and not real - for example, because there has been underdiagnosis of the disease in the past. For the period 1985-90 we have found a significant positive correlation between the yearly incidence of diagnosed childhood coeliac disease and the number of biopsies of the small intestine taken, suggesting an increase in diagnosis rather than an increase in incidence. It is possible that the wide use of endoscopy and endoscopy guided small biopsy capsules to take biopsies of the small intestine in children, which is less time consuming than using a Crosby capsule, ${ }^{22}{ }^{23}$ has contributed to the rising number of diagnoses. Another possibility to explain the apparent rise in incidence rate in childhood coeliac disease in 1993-4 compared with 1975-90, could be that the data collection in the retrospective study was incomplete. However, the risk was minimised 
by the identical method of ascertainment in both studies through the Dutch Network and National Database. The response of the paediatricians in our previous study was high: $98 \%$ compared with $92 \%$ in the prospective study. In view of the high response and the method of ascertainment it is unlikely that the data collection in either one of the studies is incomplete.

It is a fact that the use of screening methods for coeliac disease, such as the IgA class of antigliadin, antireticulin, and antiendomysium serum antibodies, is helpful to paediatricians in deciding which children should undergo a biopsy of the small bowel. Figure 2 shows that the use of serological screening tests has increased significantly during the past few years in The Netherlands: antigliadin antibodies are at present determined in $98 \%$ of the cases, whereas 20 years ago this was the case in only $44 \%$. The once popular, but not so reliable, xylose test, which is a functional sugar absorption test, has fallen into disuse: $16 \%$ in 1993-4 compared with $76 \%$ in $1975-82$. Possibly a wider use of more sensitive and specific screening tests has contributed to the increase in diagnosed coeliac disease. In our experience the relatively new antiendomysium antibody test is the most specific one. ${ }^{202425} \mathrm{In}$ 1993-4 the antiendomysium antibodies were determined in only $17 \%$ of the cases. A more frequent use of this test may increase the incidence of coeliac disease even further.

Neither can we rule out a greater awareness of coeliac disease among Dutch paediatricians as an explanation for the apparent increase in incidence. The fact that in our prospective study the paediatricians had to report coeliac disease each month to the Dutch Paediatric Surveillance Unit may have positively influenced the number of diagnoses made.

Breast feeding, which is often thought to play a protective part in coeliac disease, ${ }^{10}$ did not seem to influence the incidence in The Netherlands. From 1975 to 1990 the coeliac children did not differ from the general population of Dutch children in this aspect and in 1993-4 they even received significantly more breast feeding than the children of the general population (Table III). ${ }^{25}$ An early introduction of wheat products has also been implicated in the development of coeliac disease. ${ }^{3}$ However, according to our data, since 1985 more than $80 \%$ of the coeliac children have had wheat products introduced into their diet after the age of 6 months.

Despite the fact that all these possibilities should be considered when we seek to explain an increase in the incidence of childhood coeliac disease in The Netherlands, the increase in coeliac disease among Dutch children could still be real. This hypothesis is backed by the decreasing ratio between the number of biopsies showing subtotal villous atrophy and the total number of biopsies taken: in 1993-4 a total of 1702 biopsies were taken in The Netherlands in children under 15 years. (Sub)total villous atrophy, either in the first diagnostic biopsy or after gluten challenge, was found in 295 cases, resulting in a ratio of 1:5:8.
During 1985-90 2310 biopsies were taken in children in the same age group from six Dutch provinces, 238 of whom showed villous atrophy, resulting in a ratio of 1:9:7. On the other hand, this could also signify a better selection of patients for biopsy of the small bowel by the paediatricians over the past 10 years, parallel to the increasing use of the serological screening tests for coeliac disease.

\section{CLINICAL PICTURE OF CHILDHOOD COELIAC} DISEASE

The overall clinical picture of childhood coeliac disease at presentation in The Netherlands is that of classic coeliac disease with the triad growth failure, chronic diarrhoea, and abdominal distension as predominant symptoms. This is further supported by the fact that over the past 20 years $60 \%$ of the children have been diagnosed under the age of 2 , which is the typical age for coeliac disease to manifest itself. Since 1975 the mean age at diagnosis has been 3 years and this does not show a significant trend in time either. In Sweden, the European country with the highest incidence rate of childhood coeliac disease, most of the children, like the Dutch, present with the typical complaints of chronic diarrhea and malabsorption before the age of $2 .{ }^{5}$ It could be assumed, therefore, that the increase in incidence of coeliac disease in The Netherlands depends on the increase of classic coeliac disease. However, to see whether symptomatic coeliac disease is really increasing as in Sweden a longer period of prospective follow up is needed.

A significant linear trend was found among the classic symptoms: abdominal distension was seen less, as was growth failure in both height and weight, whereas weight loss by itself was seen more often. This could on the one hand mean that a change is ocurring in the clinical picture, but even 20 years of follow up is clearly too short to see in which direction, if any, this change is going. On the other hand, it could also mean that children with weight loss alone are now diagnosed at an earlier stage than before, or that previously these children were not diagnosed at all. In this study only a minority of the children presented with atypical coeliac disease or monosymptomatic disease $(7 \%)$. Constipation and anaemia, often considered as atypical manifestations of coeliac disease, were hardly ever present as a sole symptom, but were combined with other symptoms. Asymptomatic coeliac disease was found in two children. However, these children had Down's syndrome and as such were screened in a study on the identification of subclinical coeliac disease in children at risk for gluten sensitive enteropathy. ${ }^{20}$ Due to this study six children with Down's syndrome were found to have coeliac disease in 1994. These children were analysed in the calculations of the incidence rate, but were left out in the associated disorders, which would otherwise have led to an overrepresentation with regard to 1993 and our previous study of 1975-90.

Information on diseases associated with coeliac disease was available in $93 \%$ of the 
children diagnosed in $1993-4$, and in $65 \%$ of these diagnosed in 1975-90: no significant differences were found betwen the two periods (Table II). Cows' milk allergy, diagnosed by means of improvement of the symptoms after elimination of the offending antigen from the diet as is mostly the case in The Netherlands, was reported to be present in $6 \cdot 1 \%$ of the coeliac children. This is higher than the $2 \cdot 8 \%$ found in the general population of Dutch children. ${ }^{27}$ However, a high prevalence of cows' milk allergy has been reported before among coeliac children. ${ }^{28}$ An association of $1.5 \%$ was found with insulin dependent diabetes mellitus in 1975-94. This is consistent with the reported $1-4 \% .^{29} 30$

A positive family history in first degree relatives for coeliac disease was found in $5 \cdot 7 \%$ of the children diagnosed in 1975-94. This percentage is also consistent with the data on the literature, which report a positive family history of between $2 \%$ and $11 \%$. $^{31}$

\section{Conclusions}

The incidence of childhood coeliac disease in The Netherlands seems to increase whereas its clinical picture does not show significant variations. Many questions concerning the incidence of childhood coeliac disease remain unanswered and we can only postulate theories about why the incidence seems to increase rapidly in our country. Insufficient attention paid by paediatricians to atypical or asymptomatic forms of coeliac disease may result in an underestimate of the real incidence of the disease and active screening of these forms may increase the incidence rate further and implicate a changing clinical presentation. One possible measure to gain more insight into the pattern of coeliac disease is to study its true prevalence, including the silent and latent forms, by systemic screening (and taking biopsies from) large parts of the population.

Coeliac disease is a potentially premalignant disorder in adults ${ }^{33}$ and in children. ${ }^{34}$ Adhering to a gluten free diet protects the coeliac patient against the development of a malignancy ${ }^{33}$ and should be advised in all cases. The Paediatric Surveillance Units offer a unique opportunity to study the incidence of diseases in childhood at a national level and to make physicians aware of diseases that may lead to complications that can possibly be prevented by early treatment.

We thank Professor JM Wit for critical reading of the manuscript; EA van der Velde, department of Medical tatistics, University Hospital Leiden, Dr IJAMG Casparie-van elsen, Dutch Network and National Database of Patholog and Dr SM Kanhai for their collaboration; Mrs IJWM Gerhardt-Dijkshoorn for administrative support; Ms S Collewijn for revising the English text; and all Dutch paediatricians, without whose cooperation this study would not have been possible.

1 Greco L, Mäki M, Di Donato F, Visakorpi JK. Epidemiology of coeliac disease in Europe and the Mediterranean Area. In: Auricchio S, Visakorpi JK, eds. Common food intolerances I: epidemiology of coeliac disease. Dynamic Nutrition Research Basel: Karger, 1992: 25-44.

2 Mylotte M, Egan-Mitchell B, McCarthy CF, McNicholl B. Incidence of coeliac disease in the West of Ireland. $B M \dot{F}$ 1973; 1: 701-6.

3 Littlewood JM, Crollick AJ, Richards IDG. Childhood coeliac disease is disappearing [letter]. Lancet 1980; ii: 1359 .
4 Mäki $M$, Kallonen $K$, Lahdeaho $M L$, Visakorpi JK. Changing pattern of coeliac disease in Finland. Acta Paediatr Scand 1988; 77: 408-12.

5 Ascher H, Krantz I, Kristiansson B. Increasing incidence of coeliac disease in Sweden. Arch Dis Child 1991; 66: 608-11.

6 Weile B, Krasilnikoff PA. Low incidence rates by birth of symptomatic coeliac disease in a Danish population of children. Acta Paediatr 1992; 81: 394-8.

7 Bottaro G, Failla P, Rotolo N, Sanfilippo G, Azzaro F, Spina M, Patane R. Changes in coeliac disease behaviour over the years. Acta Paediatr 1993; 82: 566-8.

8 Magazzu G, Bottaro G, Cataldo F, Iacono G Di Donato F, Patane R, et al. Increasing incidence of childhood coeliac disease in Sicily: results of a multicenter study. Acta Paediatr 1994; 83: 1065-9.

9 Michaelsen KF, Weile B, Larsen P, Samuelson G Krasilnikoff PA. Does the low intake of wheat in Danish infants cause the low incidence rate of coeliac disease? Acta Paediatr 1993; 82: 605-6.

10 Challacombe DN. The incidence of coeliac disease and early weaning. Arch Dis Child 1983; 58: 326.

11 Cavell B. Increased prevalence of coeliac disease in Sweden: relevance of changes in feeding practices. In: Auricchio S, Visakorpi JK, eds. Common food intolerances I: epidemiology of coeliac disease. Dynamic Nutrition Research. Basel: of coeliac disease.

12 Anon. Infertility in coeliac disease (editorial). Lancet 1983; i: 453-4.

13 Depla ACIM, Bartelsman JFWM, Mulder CJJ, Tytgat GNJ Anemia: monosymptomatic coeliac disease. Hepatogastro enterology 1990; 37: 90-1.

14 George EK, Mearin ML, Van der Velde EA, Houwen RHJ, Bouquet J, Gijsbers CFM, Vandenbroucke JP. Low incidence of childhood celiac disease in The Netherlands. Pediatr Res 1995; 37: 213-8.

15 Hirasing RA. Nederlands Signaleringscentrum Kindergeneeskunde. Annual report of the Dutch Paediatric
Surveillance Unit. Leiden: TNO, 1993-4.

16 Hall SM, Glickman M. The British Paediatric Surveillance Unit. Arch Dis Child 1988; 63: 344-6.

17 Meeuwisse GW. Diagnosis criteria in coeliac disease. Acta Paediatr Scand 1970; 59: 361-3.

18 Walker-Smith JA, Guandalini S, Schmitz J, Shmerling DH, Visakorpi JK. Revised criteria for the diagnosis of coeliac disease. Report of Working Group of ESPGAN. Arch Di Child 1990; 65: 909-11.

19 Netherlands Central Bureau of Statistics, Population of the municipalities of the Netherlands at January 1st 1994 1995. The Hague: SDU/publishers, 1995.

20 George EK, Mearin ML, Bouquet J, Blomberg BME von, Stapel SO, Elburg RM van, Graaf EAB de. High frequency of coeliac disease in Down's syndrome. $F$ Pediatr 1996; 128: 555-7.

21 Dicke WK. Coeliakie. Een onderzoek naar de nadelige invloed van sommige graansoorten op de lijder van coeliakie. van sommige graansoorten op de lijder van

22 Mearin ML, Mulder CJJ. Endoscopic small bowel biopsy with a guided capsule. Acta Endoscopica 1994; 24: 393-401

23 Granot E, Goodman-Weill M, Pizov G, Sherman Y. Histological comparison of suction capsule and endoscopic small intestinal mucosal biopsies in children. $\mathcal{f}$ Pediat Gatroenterol Nutr 1993; 16: 397-400.

24 Bürgin-Wolff A, Gaze H, Hadziselimovic F, Huber $H$ Lentze MJ, Nusslé D, Reymond-Berthet G. Antigliadin and antiendomysium antibody determination for coeliac disease. Arch Dis Child 1991; 66: 941-7.

25 Hilhorst MI, Rijkers GT, van Blomberg BME, Hoogervorst BR, De Schryver JEAR, De Meer K, Houwen RHJ. Sensitiviteit en specificiteit van de antigliadine-en anti-endomysium-antilichaambepaling. Tijschr Kliadine-en anti-endomysium-an

26 Annual report of the Dutch Youth Health Care Inspection 0-4 years. 1975-94.

27 Schrander JJP, Van den Bogart JPH, Forget PP, SchranderStumpel CTRM, Kuijten RH, Kester ADM. Cow's milk protein intolerance in infants under 1 year of age: prospective epidemiological study. Eur $\mathcal{f}$ Pediatr 1993; 152: 640-4.

28 Kuitunen P, Visakorpi JK, Savilahti E, Pelkonen P. Malabsorption syndrome with cow's milk intolerance. Clinical findings and course in 54 cases. Arch Dis Child 1975; 50: 351-6.

29 Rossi TM, Albini CH, Kumar V. Incidence of celiac disease identified by the presence of serum endomysial antibodies in with chronic diarthea, short stature, or insulindn with chronic diarhea, short stare, or insulin-

30 Sigurs N, Johansson C, Elfstrand PO, Viander M, Lanner A Prevalence of coeliac disease in diabetic children and Prevalence of coeliac disease in diabetic children and
adolescents in Sweden. Acta Paediatr 1993; 82: 748-51.

31 Vitoria JC, Arrieta A, Astigarraga I, Garcia-Masdevall D, Rodriguez-Sariano J. Use of serological markers as a Rodriguez-Sariano J. Use of serological markers as a screening test in family members of patients with celia
disease. 7 Pediatr Gastroenterol Nutr 1994; 19: 304-9.

32 Mäki M, Holm K, Lipsanen V, Hällström O, Viander M, Collin $\mathrm{P}$, et al. Serological markers and HLA genes among healthy first-degree relatives of patients with coeliac disease. Lancet 1991; 338: 1350-3.

33 Holmes GKT, Prior P, Lane MR, Pope D, Allan RN Malignancy in coeliac disease. Effect of a gluten-free diet. Gut 1989; 30: 336-9.

34 Stahlberg MR, Savilahti E, Teppo L. Coeliac disease from childhood-increased risk for malignancy [abstract]. $\mathcal{F}$ Pediatr Gastroenterol Nutr 1992; 15: 346. 